\title{
Ana Akım Büyüme Modeli ve Yakınsama Hipotezlerinin Analizi: Panel Veri Yaklaşımı
}

Hakan SARIBAS, Department of Economics, Faculty of Economics and Administrative Sciences, Bulent Ecevit University, Turkey; e-mail: hakan203@yahoo.com

\section{An Analysis of the Mainstream Growth Theory and Convergence Hypotheses: A Panel Data Approach}

\begin{abstract}
In this article, we examine Solow-Swan Model, Augmented Solow-Swan Model, Absolute and Conditional Convercence hypotheses by following (Mankiw-Romer-Weil, 1992). Panel Data Fixed Effects approach is employed in six distinct country groups (all, population over one million, West, Africa, Islam and Latin) between 1990-2010 period. We found that coefficients of original model have higher values as compared to model suggestions, but these values have not come to normal levels when we control the human capital. In addition to this finding, explanatory power of independent variables in augmented model has increased and nearly explained per-worker income level. Finally, we concluded that income differences among countries may fade away in time on the condition that countries have the same structural characteristics.
\end{abstract}

Keywords

: Growth, Mankiw-Romer-Weil, Solow-Swan Model, Convergence, Cross-Section.

JEL Classification Codes : $\quad$ O40, O41, O47.

Öz

Bu çalışmada (Mankiw-Romer-Weil, 1992)'in makalesi izlenerek 1990-2010 y1lı arasındaki altı farklı ülke grubunda (Hepsi, Nüfusu bir milyondan fazla, Batı, Afrika, İslam, Latin) Solow-Swan Modeli, Genişletilmiş Solow-Swan Modeli, Mutlak ve Koşullu Yakınsama tezleri, panel veri sabit etkiler yaklaşımıyla analiz edilmektedir. Solow-Swan Modelindeki bağımsız değişkenlerin katsayıları tüm gruplar için yüksek bulunurken, genişletilmiş modelde de teorik modelin işaret ettiği oran sorunu devam etmektedir. Ayrıca, geniş̧letilmiş modelin işçi başı geliri açıklama gücü ilk modele göre yükselmiş ve neredeyse tamamına yakın bir açıklama gücü olduğu görülmüştür. Son olarak aynı yapısal unsurlara sahip olmak şartıyla ülkeler arasındaki gelir eşitsizliklerinin zaman içerisinde giderilebileceği sonucuna varılmıştır.

Anahtar Sözcükler ： Büyüme, Mankiw-Romer-Weil, Solow-Swan Model, Yakınsama, Yatay Kesit. 


\section{Giriş}

Ülkeler arasında görülen gelir eşitsizliklerinin giderilemediği, aksine en zengin ülkeler ile en fakir ülkeler arasındaki gelir açığının gittikçe arttığı gözlenmektedir. Modern büyüme literatürü bu durumu açıklamak ve politika önermeleri geliştirmek için teoriler geliştirmiştir.

Ana akım iktisat'ın büyüme modeli olan Solow-Swan modelinin ülkeler arasındaki gelir eşitsizliklerini açıklama gücü tartışılmaya devam etmektedir. (Mankiw-Romer-Weil, 1992)'in ana akım büyüme modeline uyarladıkları genişletilmiş modeli, eşitsizlikleri açıkladığını iddia etmiş ve uyarlanan bu model geniş bir kabul görmüştür.

1970'den itibaren 1980'li yılların sonuna kadar büyüme modelleri yerine kısa dönemli makro iktisat modelleri popülerdi. (Romer, 1986; Romer, 1990; Lucas, 1988)'ın makaleleri tekrar uzun dönemli bakış açısına yönelmeyi sağlamış ve içsel büyüme modelleri geliştirilmeye başlanmıştır. $\mathrm{Bu}$ makalelerde, bütün ülkelerin gelirlerinin birbirlerine yakınsayacağını öngördüğünden Solow-Swan modeli terk edilmekteydi. Ülkeler arasındaki büyük gelir farklılıklarının zaman içinde birbirlerine yaklaşmadığı müşahade edildiğinden teorinin ampirik olarak yanlışlandığı düşünülmüş ve Solow-Swan modelinden çıkış eğilimleri kuvvetlenmişti.

(Mankiw-Romer-Weil, 1992) makalesi (bundan sonra MRW) bir anlamda ders kitab1 Solow-Swan modelinden vazgeçilmesi yönündeki eğilimlere son vermiştir. Makalenin yaptığı ana katkı orijinal Solow-Swan modeline insan sermayesini dâhil ederek temel modelle gelir farklılıklarını koşullu yakınsamayla açıklayabilmesidir.

Büyüme alanındaki daha sonraki çalışmalar MRW'nin işaret ettiği istikamette ilerlemiştir. MRW, modelde hem içsel hemde dişsal olarak yer alan değişkenleri etkileyen unsurlar üzerinde durulması gerektiğini ifade etmiştir. Bu istikamette (Acemoğlu, 2009: 109-112) büyüme'nin sebeplerini yakın sebepler (Proximate Causes) ve temel sebepler (Fundamental Causes) olarak ikiye ayırmış, yakın sebepleri genişletilmiş Solow-Swan modelindeki açıklayıcı ve dışsal değişkenler (fiziksel sermaye-tasarruf, beşeri sermaye, teknoloji ve nüfus) olarak tasnif etmiş, temel sebepler olarak da şans, coğrafya, kültür ve kurumları göstermiştir. Özellikle, North ve Acemoğlu'nun öncülük ettiği yeni kurumsal iktisat'ın büyümenin kurumsal temelleri konusundaki araştırmaları alanı hâkimiyeti altına almıştır. Dolayısıyla, MRW'nin katkılarıyla, ilgi genişletilmiş Solow-Swan modelinin açıklayıcı değişkenleri yerine bu açıklayıcı değişkenleri belirleyen temel sebeplere kaymıştır.

Ders kitabı Solow-Swan modelinin MRW tarafindan genişletilerek karmaşık olan gerçek hayatı daha iyi tasvir eder hale getirilmesi, modelin içsel büyüme modelleri lehine tasfiye edilmesini önlemiş ve ana akım araştırmalarının temel modeli olarak kalmasını sağlamıştır. (Bernanke vd., 2001: Islam (2003) bu modelin esas model olduğunu vurgulamışlardır. Hem orijinal hem de genişletilmiş haliyle Solow-Swan modeli, 
üniversitelerde halen referans model olarak öğretilmekte ve araştırmalarda da yaygın olarak kullanılmaktadır.

Bu çalışmada MRW izlenerek Solow-Swan Modeli (Textbook Slow-Swan Model), Genişletilmiş Solow-Swan Modeli (Augmented Solow-Swan Model), Mutlak ve Koşullu Yakınsama hipotezleri (Absolute and Conditional Convergence) panel veri sabit etkiler (Fixed Effects) yöntemiyle test edilmektedir. Ülke grupları ve model değişkenleri bu modellere ve hipotezlere uygun olarak oluşturulmuştur. İncelenen dönem hali hazırda mevcut en yakın dönemi -1990-2010 yıllarını- kapsamaktadır. Dolayısıyla, bu çalışmamız, ele alınan dönemin yakınlığı, kullanılan değişkenlerin tamamen ana akım modelini esas alması, panel veri kullanılması, gözlem sayısının çokluğu ve özellikle oluşturulan yeni ülke gruplarıyla uygulamalı literatüre önemli bir katkı sağlamaktadır.

Çalışmamızda takip edilen sıra şu şekildedir: ikinci bölümde literatür özetlenmektedir. Üçüncü bölümde ekonometrik model değişkenlerinin ana akım modelini yansıtabilmesi için MRW'nin kısa bir özeti verilmektedir. Sonraki üç bölümde Solow-Swan Modeli ve Genişletilmiş Solow-Swan Modelleri kurulmakta ve ampirik modelle veri seti açıklanmaktadır. Yedinci bölümde modellerin öngörüsü olan mutlak ve koşullu yakınsama hipotezleri test edilirken, son bölümde elde edilen bulgular birlikte değerlendirilmektedir.

\section{Literatür Taraması}

Büyüme konusundaki görüşler Adam Smith'den beri sistematik hale gelmeye başlamasına rağmen konuyu bir model çerçevesinde ele alan çalışmalar (Ramsey, 1928)'le başlamış, (Harrod, 1939; Domar, 1946)'la devam etmiştir. Ancak, modern büyüme teorisi (neoklasik büyüme teorisi) (Solow, 1956) ve (Swan, 1956)'`n aynı yıldaki makaleleriyle asıl kimliğine kavuşmuştur. (Koopmans, 1965; Cass, 1965) tarafından da geliştirilmiştir.

Solow-Swan büyüme modeli olarak anılan bu orijinal neoklasik model, ülkelerin işçi başına düşen gelirlerinin zaman içinde aynı düzeye geleceğini öngörmekteydi. Sermaye birikimi kıt olan fakir ülkeler, daha hızlı büyüyerek sermaye birikimlerini artıracaklar ve zengin olan ülkelerin gelir düzeylerine yetişeceklerdir. Bu durum mutlak yakınsama olarak adlandırılmıştır.

1980'lerin ortasına gelindiğinde ampirik çalışmalarda Solow-Swan Modelinin yakınsama öngörüsünün yanlış olduğu söylenmekteydi. Çok sayıda ülkenin dahil edildiği veri setlerini kullanan ekonometrik çalışmalar, Solow-Swan modelini yanlışlamışlardır (Islam, 2003: 312). Bu başarısızlık alternatif büyüme modelllerinin geliştirilmesi çalışmalarına hız vermiş ve ülkeler arası farklılığı daha iyi açıklayan bir model arayışına hız verilmiştir. Bu gayretler sonucu yeni gelişen İçsel Büyüme Modellerinde azalan verimler yasası çoğunlukla terk edilmiş, insan sermayesi değişkeni de modellerde kullanılmıştır, (Romer, 1986; Lucas, 1988; Jones \& Manuelli, 1990).

Yakınsama başarısızlığının etkisiyle (Barro, 1989) Solow-Swan modelindeki yapıyı terk ederek büyüme, yatırım ve doğurganlık gibi pek çok değişken arasındaki eşanlı ilişkilere 
yönelmiş, regresyonlarında neoklasik modelin en temel açıklayıcı değişkenleri olan fiziksel sermaye ve emeğe yer vermemiştir. Başlangıç düzeyi gelir seviyesini de regresyonlarına dahil etmiştir. Barro'nun yoğunlaştığı temel değişken İçsel Büyüme Modellerinde olduğu gibi insan sermayesiydi ve insan sermayesi dahil edildiğinde regresyon bulgusunun neoklasik büyüme modelini desteklediğini ifade ediyordu. Bir kez daha ifade edilirse Barro'nun bu çalışması neoklasik büyüme modelinden çıkarılmamıştır. Yaptığı regresyonlara Barro tipi (Barro Type) regresyonlar adı verilmiştir.

Ana akım İktisadının formal büyüme regresyonunun geliştirilmesi 1980’lerin ortasındaki ampirik çalışmaların ve İçsel Büyüme Modelinin etkisi sonucunda 1992 yılında tamamlanmıştır. Regresyona uygun olan ve doğrudan Solow-Swan modelinden üretilen ilk model MRW'nin çalışmasıdır ve bu çalışma ana akım iktisadının o zamandan beri en temel büyüme regresyonu olarak kabul edilmiştir (Islam, 2003: 319). Onlar, Solow-Swan modeline insan sermayesini ekleyerek genişletmişlerdir. Genişletilmiş Solow-Swan modeli olarak anılan bu modele göre yakınsama koşulludur. Aynı yapısal koşullara sahip olan ülkeler aynı durağan denge seviyesine ulaşacaklar, farklı yapısal koşullara sahip olanlarsa kendi durağan denge seviyelerine ulaşacaklardır. Yapısal farklılıklardan dolayı yakınsama beklenmemelidir. Bu durum literatürde koşullu yakınsama olarak adlandırılmıştır.

MRW bu çalışmasında kesit veri kullanarak teknoloji hacmini ve onun büyüme oranını hata teriminin bir parçası olarak varsaymış ve böylece 'hariçte bırakılan değişken tarafgirliği 'ne (omitted variable bias) düşmüşlerdir. Bu nedenle tahmin edilen katsayıların 'tarafgir' olduğu ileri sürülmüştür. Bu problemi çözmek için (Islam, 1995) panel veri setini kullanmıştır. Ancak, panel veri seti de 'ufak örneklem tarafgirliği' ve 'kısa sıklıklar' eleştirilerine maruz kalmıştır.

MRW'nin çalışmasından sonra Solow-Swan modelinin ekonometrik olarak daha iyi nasıl tahmin edilebileceği üzerinde durulmuş, esas model olan Solow-Swan'1n teorik üstünlüğü ana akım tarafından devam ettirilmiştir. Özellikle Acemoğlu'nun çalışmalarının etkisiyle yakın sebepleri belirleyen temel sebepler üzerinde ağırlıklı olarak durulmaya başlanmıştır.

Teorinin geliştirilmesi ve MRW'ye kadar olan erken dönem ampirik çalışmalardan sonra, nispeten az sayıdaki zengin ülkeler ve çok sayıdaki az gelişmiş ülkeler arasındaki uçurumun devam etmesi sebebiyle, yakınsamayı inceleyen ampirik çalışmaların sayısında önemli bir artış olmuştur. Yakınsama hipotezini test etmek üzere literatürde iki çeşit yakınsama kavramı vardır: beta $(\beta)$-yakınsama ve sigma $(\sigma)$-yakınsama. Büyüme oranının bağımlı değişken ve başlangıç dönemi gelirin bağımsız değişken olduğu regresyona mutlak beta $(\beta)$-yakınsaması, bu bağımsız değişkene ilave edilen başka kontrol değişkenlerinin yer aldığı regresyonlara da koşullu beta $(\beta)$-yakınsaması adı verilmektedir. Koşullu beta $(\beta)$ yakınsamasındaki ilave edilen değişkenler farklılıkların kontrol edilmesini sağlamaktadır. Fakirlerin zengin olan ülkeleri yakalayacağı öngörüsü için başlangıç düzeyi gelir seviyesi değişkeninin katsayısının anlamlı olarak negatif çıkması gerekir. Literatürde beta $(\beta)$ yakınsama incelenirken yatay kesit yaklaşımı (cross-section approach) ve panel veri yaklaşımı (panel data approach) kullanılmaktadır. Ayrıca, zaman serisi yaklaşımı da (unit 
root approach) literatürde yer almaktadır. $(\sigma)$-yakınsama (distribution approach) ise başlangıç düzeyi gelir seviyesi ve kontrol değişkenleri yerine ülkelerin gelir dağılımlarının zaman içerisinde azalıp azalmadığına odaklanır. Varyansın yükselmesi ıraksamaya, azalması ise yakınsamaya işaret eder.

Literatürde yakınsamaya ilişkin yapılan çalışmaların bir kısmı mutlak yakınsama hipotezininin geçerli olduğunu bulmuşlardır (Barro \& Sala-i Martin, 1991, 1992; Sala-i Martin, 1996; Mathur, 2005; O'neil \& Van Kerm, 2008; Camarero et.al., 2008; Solanko, 2008; Desli, 2009; Liew \& Ahmad, 2009; Romero Avilla, 2009; Rapacki \& Prockniak, 2009; Palan \& Schmiedeberg, 2010; Sousa \& Pereira, 2012).

Diğer kısmı ise koşullu yakınsamanın olduğu sonucuna varmışlardır (Canevo \& Marcet, 2000; Mathur, 2005; Wo Ho, 2006; Giudici \& Mollick, 2007; Galvao \& Gomes, 2007; Dawson \& Sen, 2007; Pastor \& Serrano, 2008; Masron \& Yusop, 2008; Lei \& Yao, 2008; Bianchi et.al., 2009; Apergis et.al., 2010). Bu çalışmalardan bir kısmı farklı ülke gruplarında mutlak yakınsama bulurken diğer gruplamalarda ise koşullu yakınsamayı bulmuşlardır.

Türkiye kaynaklı çalışmalardan (Sarıbaş \& Vergil, 2013) koşullu beta ( $\beta$ )yakınsaması bulurken, (Zeren \& Yilancı, 2011) mutlak ve koşullu yakınsama bulgularına ulaşmıştır. Zaman serisi yaklaşımını kullanan çalışmalar (Akıncı \& Yılmaz, 2012; Çamurdan \& Ceylan, 2013; Abdioğlu \& Uysal, 2013; Yeşilyurt, 2014; Göğül \& Korap, 2014) yakınsamanın olduğu sonucuna varmışlardır.

Yakınsama araştırmalarında, nispeten dar kapsamlı veri setlerini kullanan, yani ülke içindeki bölgelerin birbirleri arasındaki yakınsamasını (ABD eyaletleri vs.), ve belirli bir grup ülkenin kendi aralarındaki yakınsamasını (OECD, MENA ülkeleri vs.) inceleyen çalışmalar mutlak yakınsama sonucuna varırken, daha kapsamlı ve geniş veri setlerini kullanan çalışmalar koşullu yakınsamayı bulmaktadır. Literatürde (Marcella D’Uva \& Rita De Siano, 2011; Moisescu, 2015) gibi yakınsamanın olmadığını ileri süren çalışmalar da yer almaktadır. Ülkeler arasında gelir eşitsizlikleri sürmekte, yakınsama literatüründe de mutabakat bulunmamaktadir.

\section{Orijinal Modele MRW'nin Katkısı}

Orijinal Solow-Swan modelindeki üretim fonksiyonu önemli varsayımlara sahiptir. $\mathrm{Bu}$ varsayımlar modelden elde edilen sonuçları belirlediği gibi önceki büyümenin (HarrodDomar) problemi olan bıçak sırtı problemini de sona erdirmiştir. Modeldeki varsayımlar tam rekabet, ölçeğe göre sabit getiri, üretim faktörlerinin azalan verimi, üretim faktörleri arasında ikame esnekliğinin varlığı ve sabit tasarruf oranıdır.

$\mathrm{Bu}$ varsayımlar çerçevesinde orijinal model kısaca şu sonuçları vermektedir. Kararlı denge söz konusudur. Mevcut teknoloji altında büyüme, kararlı denge noktasına yaklaştıkça azalmakta ve nihayet denge noktasında sona ermektedir. Ayrıca, başlangıç işçi başı gelir sevisesi kararlı denge seviyesinden ne kadar uzak ise büyüme o kadar yüksektir. Kararlı 
denge noktasına varıldığında, sermaye stoku ve üretim, emeğin büyüme oranı kadar büyümekte, işçi başı gelir ve işçi başı sermaye stoku ise durağan kalmaktadır. Dolayısıyla, modeldeki azalan verimler yasası farklı işçi başı gelir seviyelerinin zaman içinde birbirlerine yaklaşmasını öngörmektedir.

Orijinal modelde fiziksel sermaye ve nüfus açıklayıcı değişkenler iken MRW'nin genişlettiği modelde insan sermayesi de modele açıklayıcı değişken olarak ilave edilmektedir. MRW ilk olarak ders kitabı Solow modelini test etmiş ve dışsal açıklayıcı değişkenler olan tasarruf oranı ve nüfusun büyüme oranının kişi başı geliri sırasıyla pozitif ve negatif olarak etkilediğini bulmuşlardır. Ayrıca, sadece bu iki değişkenin kişi başı gelirin \% 50'sini açıklayabildiğini göstermişlerdir. Fakat, MRW'ye göre ampirik bulgular modelin işaret ettiği istikamette olmasına rağmen değişkenlerin gelir üzerindeki toplam etkisi çok fazladır ve doğru tahmin edilememektedir. Onlara göre etkinin fazla olmasının iki sebebi vardır: Birincisi, veri beşeri sermaye altında tasarruf oranı ve nüfusun büyüme oranı kişi başı gelir artışına yol açtığında bu gelir artışı beşeri sermayeyi de iyileştirmektedir. Dolayısıyla bu iki değişken gelir üzerinde daha yüksek bir etkiye yol açmaktadır. İkincisi, beşeri sermaye, tasarruf ve nufusun büyüme oranları ile korelasyon halindedir ve beşeri sermaye değişkeninin modelde dışta bırakılması, orijinal model değişkenlerinin tahminini hatalı yapmaktadir.

MRW, bu gerekçelerle ders kitabı Solow modeline beşeri sermaye değişkenini eklemişdir. Genişletilmiş modeli test ettiklerinde ise fiziksel sermaye, beşeri sermaye ve nüfusun büyüme oranının kişi başı geliri \%80 oranında belirlediğini bulmuşlardır. Bir başka ifadeyle, kişi başı gelir sadece bu üç değişkenle neredeyse tamamen açıklanmış olmaktadır. Ayrıca, genişletilmiş modelde, tasarruf ve nüfusun büyüme oranlarının gelir üzerindeki etkileri orijinal Solow modelindeki oranlarda bulunmuştur. Genişletilmiş Solow modelinde kişi başı gelir üzerindeki yüksek etkilerin gerilemesi yukarıda ifade edilen gerekçelerin haklılığını gösterdiğini belirtmişlerdir.

MRW, orijinal Solow modelini genişletip ampirik başarısını gösterdikten sonra orijinal Solow modeline yöneltilen yakınsama eleştirisine cevap vermişlerdir. Yukarıda ifade edildiği gibi modelin tahmin ettiği ülkelerin kişi başı gelirlerinin birbirine yakınsayacağı hipotezi ekonometrik araştırmalar neticesinde ret edilmiş ve ülkelerin birbirlerine yakınsamadığı gözlenmiştir. MRW, genişletilmiş modelden yola çıkarak yakınsamanın beklenilmemesi gerektiğini zira her ülkenin açıklayıcı değişkenlerinin farklı olmasından dolayı ülkelerin kendi kararlı dengelerine ilerlediğini, yakınsama olabilmesi için de açıklayıcı değişkenlerin aynı olması gerektiğini söylemişlerdir. Kısaca açıklamak gerekirse, kararlı dengede işçi başı gelir ve işçi başı sermaye, tasarruf oranına, nüfusun büyüme oranına ve üretim fonksiyonuna (teknoloji) bağlıdır. Dolayısıyla, bu özelliklerdeki bir farklılık başka kararlı dengeleri işaret ettiğinden işçi başı gelir ve işçi başı sermaye düzeyleri değişik seviyeler alır. Ülkelerin tasarruf oranları, nüfuslarının büyüme oranı ve üretim fonksiyonları farklı olduğundan her ülke kendi kararlı dengesine doğru ilerler. Açıklayıcı değişkenler kontrol edildiğinde yani bu özelliklerdeki benzerlikler ise benzer işçi başı gelirleri üretir ve yakınsama gerçekleşir. $\mathrm{Bu}$ açıklama büyüme literatürüne şartlı 
yakınsama hipotezi olarak girmiştir. Dolayısıyla, şartlı yakınsama hipotezi ülkeler arasında görülen büyüme ve gelir farklılıklarını güçlü bir biçimde açıklayabilmektedir.

MRW, son olarak Solow modelinin tahminlerinden olan sermaye akışkanlığındaki farklı getiri oranlarını ampirik olarak incelemiş ve fakir ülkelerin daha yüksek beşeri ve fiziksel sermaye getiri oranlarına sahip olduğunu bularak modelin tahmininin isabetli olduğunu göstermişlerdir. İçsel büyüme modelleri sabit veya artan getiri oranlarını varsaymaktadır. Dolayısıyla, içsel büyüme modelleriyle Solow büyüme modeli arasındaki en önemli farklardan birisi olan azalan verimler yasasının gerekliliği bir defa daha teyit edilmektedir.

\section{Solow-Swan Modeli}

Yukarıda özelliklerinden kısaca bahsettiğimiz ve Solow-Swan modelinin esasını oluşturan neoklasik üretim fonksiyonu matematiksel olarak (1) nolu denklemde, modelin çözümü neticesinde elde edilen durağan denge koşulu (2) nolu denklemde verilmiştir.

$$
\begin{aligned}
& Y(t)=K(t)^{\propto}(A(t) L(t))^{1-\propto} \\
& k^{*}=\left[\frac{s}{(n+g+\delta)}\right]^{\frac{1}{(1-\alpha)}}
\end{aligned}
$$

Solow modelinde $\mathrm{Y}=$ Üretim, $\mathrm{L}=$ Emek, $\mathrm{A}=$ teknoloji düzeyi, $\mathrm{s}=$ tasarruf oranı, $\mathrm{n}$ ve g emek ve teknolojinin büyüme oranını göstermektedir. $\delta$ sermayenin yıpranma payıdır. Modelde sermaye ve emek üretim faktörleridir ve üretimden aldıkları pay marjinal ürünlerdir. Tasarruf oranı, teknolojik gelişme ve nüfusun büyüme oranlarının değerleri dışsal ve sabitdir. Matematiksel olarak hesaplanan kararlı denge sermaye emek oranını üretim fonksiyonunda yerine yazıp, daha sonra logaritmasını aldığımızda kararlı denge kişi başı reel gelirini aşağıdaki gibi buluruz: ${ }^{1}$

$$
\ln \left[\frac{Y(t)}{L(t)}\right]=\ln A(0)+g t+\frac{\propto}{1-\alpha} \ln (s)-\frac{\propto}{1-\alpha} \ln (n+g+\delta)
$$

Tasarruf oranının reel gelir üzerindeki etkisi pozitif iken nüfusün büyüme oranının etkisi negatifdir. $\propto / 1-\propto$ oranı, kişi başı gelirin tasaruf oranı ve nüfusun büyüme oranına göre elastikiyetini göstermektedir ve sırasıyla 0.5 ve -0.5 civarında olduğu düşünülmektedir. Bilginin ve sermayenin yıpranmasının herhangi bir ülkeye has olmadığı varsayıldığında $g$ ve $\delta$ ülkeler arasinda sabitdir.

1 Bu çalışmamızda Solow-Swan modelinin matematiksel izahına yer verilmemiştir. MRW'nin tam matematiksel çözümü için Sorensen and Whitta-Jacobsen (2010:156-181)'e bakınız. Ayrıca, Türkçe izahlı detaylı çözüm irtibat adresinden istenebilir. 
Solow modelinde $A(0)$ terimine yüklenen anlam çok önemlidir. Bu terim teknolojiyi ifade ettiği gibi, iklimi, hazır doğal kaynakları, kurumları ve benzeri diğer unsurları ihtiva eder. Bu unsurlar da ülkeden ülkeye değiştiğinden MRW bu terimi aşağıdaki gibi tarif etmektedir:

$$
\ln A(0)=a+\epsilon
$$

a sabit, $\epsilon$ ise ülkeye göre değişen şokdur. Zamanı sıfır olarak alıp, yukarıdaki eşitliği denklemde yerine yazdığımızda modelin verilere uygulanacak ekonometrik formülüne ulaşılmaktadır:

$$
\ln \left(\frac{Y}{L}\right)=a+\frac{\propto}{1-\alpha} \ln (s)-\frac{\propto}{1-\alpha} \ln (n+g+\delta)+\epsilon
$$

\section{Ampirik Model ve Veri Seti}

Modelde tasarruf ve nüfusun büyüme oranlarının kişi başı reel gelir üzerindeki etkisinin yönü ve miktarı tahmin edilebilmektedir. Çalışmada Penn Dünya Tablolarından (Penn World Tables) temin edilen veri setini kullanılmış ve 1990-2010 arasındaki 20 yıllık dönemi kapsamaktadır (Heston vd. 2012) ${ }^{2}$. Hesaplamalarda kullanılan veriler aşağıdaki gibidir:

ki = Kişi başı 2005 fiyatlarıyla Yatırımların GSYİH'ya oranı (Investment Share of GDP Per Capita at 2005 constant prices)

rgdpwok = 2005 fiyatlarıyla işçi başı gelir (2005 International dollar per worker (2005

I\$/worker))

Pop $=$ Nüfus (Population (in thousands))

Okul $($ School $)=$ Kişi başı beşeri sermaye endeksi (Index of human capital per person, based on years of schooling (Barro/Lee, 2012) and returns to education (Psacharopoulos, 1994)).

Veri setindeki ülkeler 2010 yılı itibariyle ele alınmıştır. Mümkün olan en yüksek veri setine uşabilmek için 1990-2010 aralığ seçilmiştir. Her ülkeye ait 20 yıllık veriler beşer yıllık dört döneme ayrılmış ve dönem ortalamaları kullanılarak panel veri oluşturulmuştur. Ülkeler, bütün ülkeler (hepsi), nüfusu bir milyondan fazla olan ülkeler (nüfus), Batı, Afrika, İslam, ve Latin ülkeleri olarak gruplandırılmış ve her bir grup için tahmin edilmiştir. İlk örneklemde bütün ülkeler dahil edilirken, ikincisinde nüfusu bir milyondan fazla olan ülkelere yer verilmiş, üçüncü, dördüncü, beşinci ve altıncı örneklemlerdeyse sırasıyla sadece Batı, Afrika, İslam ve Latin ülkeleri alınmıştır³ . Büyüme literatüründeki temel sebeblerden olan kurumlar ve kültür hipotezleri beraber düşünüldüğünde medeniyeti ifade eder. Batı, 
İslam, Afrika ve Latin medeniyetlerine ait ülkeler bu başlıklar altında bir araya getirilmiştir (Acemoglu, 2009:109-112; Braudel, 2014:29-71; Huntington, 2015: 13-107).

Ders kitabı Solow modelinin panel veri sabit etkiler (Fixed effects) yaklaşımıyla tahmini Tablo 1'de verilmiştir.

Tablo: 1

Solow-Swan Modelinin Tahmini

\begin{tabular}{|c|c|c|c|c|c|c|}
\hline \multicolumn{7}{|c}{ Bağıml Değişken: 2010 yılı log (işçi başı GSYİH) } \\
\hline Örneklem & Hepsi & Nüfus & Batı & Afrika & İslam & Latin \\
\hline Gözlem Sayıs1 & 652 & 544 & 109 & 108 & 126 & 80 \\
\hline \multirow{2}{*}{ Sabit } & $4.07 * * *$ & $5.06^{* * *}$ & $3.52^{* * *}$ & $3.59^{* * *}$ & $5.07 * * *$ & $6.45^{* * *}$ \\
& $(0.20)$ & $(0.22)$ & $(0.40)$ & $(0.44)$ & $(0.60)$ & $(1.11)$ \\
\hline \multirow{2}{*}{$\ln (\mathrm{I} / \mathrm{GDP})$} & $1.20^{* * *}$ & $0.96^{* * *}$ & $0.84 * *$ & $0.68^{* * *}$ & $0.41^{* *}$ & -0.14 \\
& $(0.09)$ & $(0.09)$ & $(0.25)$ & $(0.16)$ & $(0.18)$ & $(0.39)$ \\
\hline \multirow{2}{*}{$\ln (\mathrm{n}+\mathrm{g}+\delta)$} & $-1.62^{* * *}$ & $-2.54 * * *$ & 0.14 & -0.78 & $-1.68^{* * *}$ & $-2.55^{* *}$ \\
& $(0.20)$ & $(0.20)$ & $(0.43)$ & $(0.51)$ & $(0.61)$ & $(1.11)$ \\
\hline$R^{2}$ & 0.49 & 0.60 & 0.23 & 0.45 & 0.44 & 0.31 \\
\hline
\end{tabular}

Not: Parantez içi değerler standart sapmalart göstermektedir. Yıldızlar anlamlıllkları ifade etmektedir: *** yüzde 99, ** yüzde 95 ve * yüzde $90 .(\mathrm{g}+\delta)$ değeri 0.05 olarak alınmıştır.

Elde edilen tahmin sonuçlarına baktığımızda modellerde katsayıların işaretlerinin Solow modelinin işaret ettiği yönde olduğu bulunmuştur. Katsayıların anlamlılık seviyesinin genellikle yüzde 99 seviyesinde olduğu görülmektedir. Gözlem sayısının en geniş olduğu ilk iki modelde, ülkeler arasındaki kişi başı gelir farklılıklarının yaklaşık üçte ikisinin sadece tasarruf ve nüfusun büyüme oranlarındaki farklılıklarla açılanabilmektedir. Batı ve Latin ülkelerinde bu oran beşte bir ve üçde bir seviyesindedir. Solow modelinde sermayenin pay1 $\alpha=1 / 3$ oranında olduğundan eğim yani $\ln (I / G)$ katsayısı 0.5 civarında olmalıdır. Tüm modellerde bu oran 0.5 'in çok üzerindedir (Latin'de anlamlı değil). Örneğin, ilk modelde elde edilen eğim 1.20 'dir ve dolayısıyla 0.50 'nin çok üzerinde bulunmuştur. Eğimin 2 standart sapma aşağ 1 ve üstü yüzde 95 güven aralığı olduğundan elde edilen tahminin yüzde 95 güven aralığı (1.02-1.38) olmaktadır. Dolayısıyla, tahmin edilen eğim anlamlı olarak 0.5 'in çok üzerinde yer almaktadır. Modellerden elde edilen $\alpha$ değerleri sırasıyla $0.54,0.49$, $0.46,0.40$ ve 0.29 'dur. Bağımsız değişkenlerin bağımlı değişken üzerindeki etkisi Solow modelinin işaret ettiği seviyenin çok üzerinde bulunmuştur. Bir başka deyişle, örneğin, tasarruf oranının kişi başı gelir seviyesi üzerindeki etkisi ders kitabı Solow modelinden çok daha fazladır. Etkinin boyutu konusunda ders kitabı Solow modeli başarılı değildir.

\section{Genişletilmiş Solow-Swan Modeli}

MRW, ders kitabı Solow modelinde model dışında bırakılan ve bu yüzden hatalı tahmin sonuçları veren insan sermayesi değişkeni açıklayıcı değişken olarak modele dâhil 
ederek ders kitabı Solow modelini düzeltmişlerdir. Sermaye artık sadece fiziksel sermaye değil insan sermayesi olarak ikiye ayrılmaktadır. Düzeltilmiş üretim fonksiyonu artık aşağıdaki gibidir:

$$
Y(t)=K(t)^{\alpha} H(t)^{\beta}(A(t) L(t))^{1-\alpha-\beta}
$$

Üretim fonksiyonuna yeni giren insan sermayesi değişkeni H olarak gösterilmiştir. İnsan sermayesinin fiziksel sermayeyle aynı oranda yıprandığ verimlere sahip olması $(\alpha+\beta<1)$ modeldeki öne çıkan varsayımlardır. Üretim fonksiyonunu kişi başı fiziksel sermaye ve insan sermayesi olarak zaman içinde nasıl değiştiği fonksiyonlar olarak hesapladıktan sonra durağan denge denklemlerine ulaş1lır. Daha sonra durağan denge denklemleri üretim fonksiyonunda yerine yazılıp logaritması alındığında aşağıdaki denkleme ulaşılır, (MRW, 1992):

$$
\ln \left[\frac{Y(t)}{L(t)}\right]=\ln A(0)+g t-\frac{\alpha+\beta}{1-\alpha-\beta} \ln (n+g+\delta)+\frac{\alpha}{1-\alpha-\beta} \ln \left(s_{k}\right)+\frac{\beta}{1-\alpha-\beta} \ln \left(s_{h}\right)
$$

Denklem, kişi başı gelirin nüfusun büyüme oranıyla fiziksel ve insan sermayesindeki büyüme oranlarının sırasıyla negatif ve pozitif bir fonksiyonu olduğunu ifade etmektedir. İnsan sermayesi değişkenini tam olarak veren bir veri bulmak oldukça zor olduğundan tahminimizde kullandığımız insan sermayesi değişkeni Penn Dünya Tabloları veri setinden alınmıştır ${ }^{5}$.

Düzeltilmiş Solow-Swan modelinin panel veri sabit etkiler yaklaşımıyla tahmini tablo 2'de verilmiştir. Tabloda görülen modellerin hepsinde anlamlı bulunan bağımsız değişkenlerin işaretleri modelin ifade ettiği istikamettedir. Anlamlı olan değişkenlerin işaretlerinin doğru olmasının yanında elde edilen katsayıların hepsi bütün modellerde anlamlı çıkmamıştır. Ayrıca, en geniş gözlem sayısına sahip modelde kişi başı gelirin yüzde 72'i sadece nüfusun, insan sermayesinin ve fiziksel sermayenin büyüme oranları tarafindan açıklanabilmektedir. Batı modeli hariç diğer modellerde bu oran sırasıyla 0.78, 0.76, 0.71 ve 0.58 gibi yüksek seviyededir.

Genişletilmiş modelde katsayıların değerleri faktörlerin üretimden aldıkları paylarının bir fonksiyonudur. Ders kitabı Solow modelinde $\alpha=1 / 3$ değerindedir. $\beta$ değeri MRW'de 1/3 ile $1 / 2$ arasında olduğu ileri sürülmüştür. Bu oranlara Sorensen and A-Jacobsen (2010)'de katılmaktadır. $\alpha=\frac{1}{3}$ ve $\beta=\frac{1}{3}$ olarak alındığında modeldeki tasarruf oranı ve insan sermayesi katsayılarının birbirine eşit ve 1 (bir) civarında yer almaları gerekir. Katsayıların standart sapmalarının 2 katı aşağı ve yukarısı yüzde 95 güven aralığını temsil ettiğinden katsayıların aralıkları aşağıdaki gibidir: 
Model: Hepsi $-0.48<0.66<0.84$ ve $2.68<3.08<3.48$

Model: Nüfus $-0.33<0.49<0.65$ ve $2.69<3.07<3.45$

Model: Bat1 $-0.35<0.83<1.31$ ve $0.28<1.26<2.24$

Model: İslam $-0.03<0.41<0.79$ ve $1.07<1.97<2.87$

Görüldüğü gibi tasarruf ve insan sermayesinin oranının kişi başı gelir üzerindeki etkisinin boyutu modelin işaret ettiği boyutlarda değildir. Dolayısıyla, ders kitabı Solow modelinde hesaplanan fazla etkinin genişletilmiş modelde -Batı modeli hariç- düzelmediği görülmektedir.

Tablo: 2

Genișletilmiș Solow-Swan Modelinin Tahmini

\begin{tabular}{|c|c|c|c|c|c|c|}
\hline \multicolumn{7}{|c|}{ Bağımlı Değişken: 2010 yılı log (işçi başı GSYİH) } \\
\hline Örneklem & Hepsi & Nüfus & Bat1 & Afrika & İslam & Latin \\
\hline Gözlem Sayısı & 536 & 476 & 109 & 92 & 90 & 76 \\
\hline Sabit & $\begin{array}{l}1.99 * * * \\
(0.23) \\
\end{array}$ & $\begin{array}{l}2.61 * * * \\
(0.24) \\
\end{array}$ & $\begin{array}{l}3.04 * * * \\
(0.43) \\
\end{array}$ & \begin{tabular}{|l}
$3.32 * * *$ \\
$(0.33)$ \\
\end{tabular} & $\begin{array}{l}2.84 * * * \\
(0.70)\end{array}$ & $\begin{array}{l}2.40 * * \\
(1.08) \\
\end{array}$ \\
\hline $\ln (\mathrm{I} / \mathrm{GDP})$ & $\begin{array}{l}0.66 * * * \\
(0.09)\end{array}$ & $\begin{array}{l}0.49 * * * \\
(0.08)\end{array}$ & $\begin{array}{l}0.83^{* * * *} \\
(0.24)\end{array}$ & $\begin{array}{l}-0.00 \\
(0.16)\end{array}$ & $\begin{array}{l}0.41 * * \\
(0.19)\end{array}$ & $\begin{array}{l}-0.49 \\
(0.30)\end{array}$ \\
\hline $\ln (\mathrm{n}+\mathrm{g}+\delta)$ & $\begin{array}{l}0.43^{*} \\
(0.22)\end{array}$ & $\begin{array}{l}-0.12 \\
(0.22) \\
\end{array}$ & $\begin{array}{l}-0.01 \\
(0.42) \\
\end{array}$ & $\begin{array}{l}-0.60 \\
(0.37) \\
\end{array}$ & $\begin{array}{l}0.34 \\
(0.66)\end{array}$ & $\begin{array}{l}1.10 \\
(1.04) \\
\end{array}$ \\
\hline $\ln (\mathrm{Okul})$ & \begin{tabular}{|l}
$3.08 * * *$ \\
$(0.20)$
\end{tabular} & \begin{tabular}{|l}
$3.07 * * *$ \\
$(0.19)$
\end{tabular} & $\begin{array}{l}1.26^{* *} \\
(0.49)\end{array}$ & \begin{tabular}{|l}
$3.20 * * *$ \\
$(0.40)$
\end{tabular} & $\begin{array}{l}1.97 * * * \\
(0.45)\end{array}$ & $\begin{array}{l}4.04 * * * \\
(0.82)\end{array}$ \\
\hline$R^{2}$ & 0.72 & 0.78 & 0.29 & 0.76 & 0.71 & 0.58 \\
\hline
\end{tabular}

Not: Parantez içi değerler standart sapmaları göstermektedir. $(g+\delta)$ değeri 0.05 olarak alınmıştır.

\section{Yakınsama}

Solow modelinde ülkelerin kendi kararlı dengelerine sahip oldukları, kişi başı gelir seviyesi düşük olan ülkenin yüksek olan ülkeye göre daha hızlı büyüyeceği, sermaye birikimi artıkça büyüme oranının düşeceği ve nihayet kararlı dengede kişi başı gelir büyümesinin sıfirlanacağı ileri sürülmektedir. Kişi başı geliri belirleyen değişkenlerdeki farklılıklar farklı kararlı dengelere yol açmaktadır. Yani, kararlı denge belirleyicileri olan nüfusun büyüme oranı, tasarruf oranı ve insan sermayesindeki ayniyetler aynı kararlı dengeyi ifade edeceğinden ülkeler arasında yakınsama olacaktır. Modelde düşük gelirlilerin daha hızlı büyümesinin sebebi azalan verimler yasasıdır $(\alpha+\beta<1)$. İçsel büyüme modellerinin varsayımı olan $\alpha+\beta=1$ veya $\alpha+\beta>1$ durumunda yakınsama olmaz. Biraz daha iyi kişi başı gelir belirleyicisine sahip olan ülke sonsuza kadar daha hızlı büyür. $\mathrm{Bu}$ bölümde bu hipotezler yani ders kitabı Solow modelinin mutlak yakınsama hipotezi, sonra genişletilmiş modelin şartlı yakınsama hipotezi test edilmektedir.

Solow modelinde yakınsama hızı aşağıdaki denklemle ifade edilir:

$$
\frac{d \ln (y(t))}{d t}=\lambda\left[\ln \left(y^{*}\right)-\ln (y(t))\right]
$$




$$
\lambda=(n+g+\delta)(1-\alpha-\beta)
$$

Büyüme oranının belirleyicilerini bulmak için matematiksel olarak bağımlı değişkeni büyüme oranı olarak ifade edip gerekli matematiksel işlemleri yaptıktan sonra büyüme oranının belirleyicilerinin görüldüğü aşağıdaki denkleme ulaşılır, (MRW, 1992):

$$
\begin{aligned}
& \ln \left(y(t)-\ln (y(0))=\left(1-e^{-\lambda t}\right) \frac{\alpha}{1-\alpha-\beta} \ln \left(s_{k}\right)+\left(1-e^{-\lambda t}\right) \frac{\beta}{1-\alpha-\beta} \ln \left(s_{h}\right)-\right. \\
& \left(1-e^{-\lambda t}\right) \frac{\alpha+\beta}{1-\alpha-\beta} \ln (n+g+\delta)-\left(1-e^{-\lambda t}\right) \ln (y(0))
\end{aligned}
$$

Denklemde kişi başı gelirin büyüme oranı, genişletilmiş modeldeki değişkenler ve başlangıç düzeyi gelir seviyesinin bir fonksiyonudur. Önündeki negatif işaretten dolayı kişi başı gelirin büyüme oranıyla başlangıç düzeyi gelir seviyesi arasında ters yönlü bir ilişki bulunmaktadır.

Kararlı denge belirleyicilerinin olmadığı, yani sadece kişi başı gelirin büyüme oranıyla başlangıç düzeyi gelir seviyesi arasındaki ilişkinin test edildiği mutlak yakınsama hipotezinin sonuçları Tablo 3'de görülmektedir.

\begin{tabular}{|c|c|c|c|c|c|c|}
\hline \multicolumn{7}{|c|}{ Bağımlı Değişken: Kişi başı GSYİH logaritma farkı: 1990-2010 } \\
\hline Örneklem & Hepsi & Nüfus & Batı & Afrika & İslam & Latin \\
\hline Gözlem sayısı & 637 & 529 & 109 & 102 & 123 & 79 \\
\hline Sabit & $\begin{array}{l}-1.11 \text { *** } \\
(0.17)\end{array}$ & $\begin{array}{l}-0.88 * * * \\
(0.17)\end{array}$ & $\begin{array}{l}0.22 \\
(0.66)\end{array}$ & $\begin{array}{l}-1.09^{*} \\
(1.59)\end{array}$ & $\begin{array}{l}-2.63 * * * \\
(0.45)\end{array}$ & $\begin{array}{l}-0.47 \\
(1.04)\end{array}$ \\
\hline $\ln (Y 90)$ & $\begin{array}{l}-0.07 * \\
(0.04)\end{array}$ & $\begin{array}{l}-0.14 * * * \\
(0.04)\end{array}$ & $\begin{array}{l}-0.40 * * * \\
(0.14)\end{array}$ & $\begin{array}{l}-0.09 \\
(0.17)\end{array}$ & $\begin{array}{l}0.33 * * * \\
(0.11)\end{array}$ & $\begin{array}{l}-0.26 \\
(0.25)\end{array}$ \\
\hline$R^{2}$ & 0.28 & 0.29 & 0.33 & 0.27 & 0.28 & 0.19 \\
\hline
\end{tabular}

Tablo: 3

Mutlak Yakınsama Testi

Not: Parantez içi değerler standart sapmaları göstermektedir. Y90 kişi başı GSYİH'nın 1990 yılındaki değeridir.

Hepsi, Nüfus, Batı, Afrika ve Latin modellerinindeki katsayı işareti modelin işaret ettiği istikamette negatif bulunurken, İslam modelinde anlamlı olarak pozitif çıkmıştır. Sadece Latin ve Afrika gruplarında katsayı anlamlı değildir ve Latin hariç bütün modellerde R2 değerleri 0.30 civarındadır. Dolayısıyla, Hepsi, Nüfus ve Batı modellerinde mutlak yakınsama hipotezi desteklenirken, diğer modellerde desteklenmemektedir. En yüksek gözlem sayısına sahip modellere bakıldığında fakirlerin zenginlerden daha hızlı büyüme eğiliminde olduğu görülmektedir.

Regresyonlara kontrol değişkenleri olarak önce yatırım ve nüfus değişkenlerini ekleyerek Tablo 4'deki sonuçlara ulaştık. Buna göre İslam modeli hariç tüm modellerde $\ln$ (Y90) katsayısı negatifdir ve sadece nüfus modelinde anlamlıdır. Dolayısıyla, sadece nüfus modelinde şartlı yakınsama bulunarak fakirlerin zenginlerden daha hızlı büyüdüğü söylenebilmektedir. 
Tablo: 4

Koșullu Yakınsama Testi

\begin{tabular}{|c|c|c|c|c|c|c|}
\hline \multicolumn{7}{|c|}{ Bağımlı Değişken: Kişi başı GSYİH logaritma farkı: 1990-2010 } \\
\hline Örneklem & Hepsi & Nüfus & Bat1 & Afrika & İslam & Latin \\
\hline Gözlem Sayısı & 637 & 529 & 109 & 102 & 123 & 79 \\
\hline Sabit & $\begin{array}{l}0.89 \text { **** } \\
(0.30)\end{array}$ & \begin{tabular}{|l|}
-0.26 \\
$(0.36)$ \\
\end{tabular} & $\begin{array}{l}1.02 \\
(0.70)\end{array}$ & \begin{tabular}{|l|}
-0.49 \\
$(0.97)$ \\
\end{tabular} & \begin{tabular}{|l|}
-1.56 \\
$(0.84)$ \\
\end{tabular} & $\begin{array}{l}0.61 \\
(2.18)\end{array}$ \\
\hline $\ln (\mathrm{Y} 90)$ & $\begin{array}{l}-0.07 \\
(0.04)\end{array}$ & $\begin{array}{l}-0.19 * * * \\
(0.05)\end{array}$ & $\begin{array}{l}-0.23 \\
(0.16)\end{array}$ & $\begin{array}{l}-0.17 \\
(0.18)\end{array}$ & $\begin{array}{l}0.27 * * \\
(0.12)\end{array}$ & $\begin{array}{l}-0.30 \\
(0.26)\end{array}$ \\
\hline $\ln (\mathrm{I} / \mathrm{GDP})$ & $\begin{array}{l}-0.04 \\
(0.10)\end{array}$ & \begin{tabular}{|l|}
0.01 \\
$(0.11)$
\end{tabular} & $\begin{array}{l}-0.29 \\
(0.37)\end{array}$ & $\begin{array}{l}0.26 \\
(0.24)\end{array}$ & $\begin{array}{l}-0.04 \\
(0.19)\end{array}$ & $\begin{array}{l}0.27 \\
(0.54)\end{array}$ \\
\hline $\ln (\mathrm{n}+\mathrm{g}+\delta)$ & $\begin{array}{l}-0.18 \\
(0.22)\end{array}$ & $\begin{array}{l}-0.50^{* * *} \\
(0.25)\end{array}$ & $\begin{array}{l}-1.58 * * * \\
(0.59)\end{array}$ & $\begin{array}{l}-0.66 \\
(0.80)\end{array}$ & $\begin{array}{l}-0.95 \\
(0.63)\end{array}$ & $\begin{array}{l}-1.54 \\
(1.59)\end{array}$ \\
\hline$R^{2}$ & 0.28 & 0.29 & 0.40 & 0.28 & 0.30 & 0.21 \\
\hline
\end{tabular}

Not: Parantez içi değerler standart sapmaları göstermektedir. Y90 kişi başı GSYİH'nın 1990 yılındaki değeridir.

Beşeri sermaye modellere kontrol değişkeni olarak ilave edildiğinde Tablo 5'deki sonuçları aldık. Nüfus ve Afrika ülkeri gruplarında şartlı yakınsama anlamlıdır. Buna göre yatırım, nüfus ve insan sermayesi kontrol edildiğinde fakirler zenginlerden daha hızlı büyümektedir. Diğer modellerde bu sonuç geçerli değildir.

Tablo: 5

Koşullu Yakınsama Testi

\begin{tabular}{|c|c|c|c|c|c|c|}
\hline \multicolumn{7}{|c|}{ Bağımlı Değişken: Kişi başı GSYİH logaritma farkı: 1990-2010 } \\
\hline Örneklem & Hepsi & Nüfus & Bat1 & Afrika & İslam & Latin \\
\hline Gözlem Sayısı & 524 & 464 & 109 & 87 & 88 & 76 \\
\hline Sabit & $\begin{array}{l}-0.76^{* *} \\
(0.34)\end{array}$ & $\begin{array}{l}-0.05 \\
(0.41) \\
\end{array}$ & \begin{tabular}{|l|}
0.91 \\
$(0.71)$
\end{tabular} & $\begin{array}{l}0.44 \\
(1.13) \\
\end{array}$ & $\begin{array}{l}-1.99 * \\
(1.05) \\
\end{array}$ & $\begin{array}{l}-0.40 \\
(2.35) \\
\end{array}$ \\
\hline $\ln (Y 90)$ & $\begin{array}{l}-0.13^{*} \\
(0.08) \\
\end{array}$ & $\begin{array}{l}-0.26^{* * * *} \\
(0.08)\end{array}$ & \begin{tabular}{|l|}
-0.25 \\
$(0.16)$ \\
\end{tabular} & $\begin{array}{l}-0.49^{*} \\
(0.26) \\
\end{array}$ & $\begin{array}{l}0.81 * * * \\
(0.22)\end{array}$ & $\begin{array}{l}-0.47 \\
(0.31) \\
\end{array}$ \\
\hline $\ln (\mathrm{I} / \mathrm{GDP})$ & $\begin{array}{l}-0.06 \\
(0.13)\end{array}$ & $\begin{array}{l}0.02 \\
(0.13)\end{array}$ & $\begin{array}{l}-0.27 \\
(0.37)\end{array}$ & $\begin{array}{l}-0.03 \\
(0.34)\end{array}$ & $\begin{array}{l}-0.76^{* * * *} \\
(0.25)\end{array}$ & $\begin{array}{l}0.05 \\
(0.58)\end{array}$ \\
\hline $\ln (\mathrm{n}+\mathrm{g}+\delta)$ & $\begin{array}{l}-0.12 \\
(0.30\end{array}$ & $\begin{array}{l}-0.54 \\
(0.33)\end{array}$ & $\begin{array}{l}-1.62 * * * \\
(0.59)\end{array}$ & $\begin{array}{l}-0.67 \\
(0.83)\end{array}$ & $\begin{array}{l}-1.45^{*} \\
(0.81)\end{array}$ & $\begin{array}{l}-0.24 \\
(1.98)\end{array}$ \\
\hline $\mathrm{Ln}(\mathrm{Okul})$ & $\begin{array}{l}0.12 \\
(0.35)\end{array}$ & $\begin{array}{l}0.27 \\
(0.39)\end{array}$ & \begin{tabular}{|l|}
0.47 \\
$(0.70)$
\end{tabular} & $\begin{array}{l}1.91^{*} \\
(1.13)\end{array}$ & $\begin{array}{l}-1.65 * * \\
(0.70)\end{array}$ & $\begin{array}{l}2.58 \\
(1.67)\end{array}$ \\
\hline$R^{2}$ & 0.29 & 0.31 & 0.40 & 0.36 & 0.57 & 0.24 \\
\hline
\end{tabular}

Not: Parantez içi değerler standart sapmaları göstermektedir. Y90 kişi başı GSYİH'nın 1990 yılındaki değeridir.

\section{Sonuç}

Ana akım iktisadının genişletilmiş büyüme modeli, son 20 yıllık verilerle işçi başı geliri ve ülkeler arasındaki gelir eşitsizliklerini açıklamada tam olarak başarılı değildir. Solow-Swan modelinde sadece yatırım ve nüfus değişkenleri açıklayıcı değişsen olduklarından ilk testte bu değişkenlere yer verilmiştir. Alınan sonuçlara göre altı ülke gurubunun ekseriyetinde açıklayıcı değişkenlerin katsayıları teorik olarak beklenen istikamette olmuş ve anlamlı bulunmuşur. Altı modelin hepsinde de ortak olan unsur katsayıların büyüklüğünün teorik modelin öngördüğü seviyelerin çok üzerinde olmasıdır. 
Orijinal teorik model olan Solow-Swan modelinde insan sermayesi değişkeni de kontrol edildiğinde tüm modellerdeki nüfus katsayısının büyüklüğü sorunu artmakta, fakat batı hariç diğer modellerde tasarruf katsaysı azalmaktadır. Modellerin açıklama gücünün de arttığını görüyoruz. Mesela, nüfusu bir milyondan fazla olan ülkelerin olduğu modelde, yatırım, nüfus ve insan sermayesi değişkenleri işçi başı geliri yüzde 78 oranında açıklayabilmektedir. Altı modelin hepsinde insan sermayesi değişkeni 0.99 düzeyinde anlamlıyken, tasarruf değişkeni sadece Afrika ve Latin gruplarında anlamsız bulunmuştur.

Ülkeler arasındaki işçi başı gelir eşitsizliklerinin kalmayacağı yani ülkelerin birbirlerine mutlak olarak yakınsayacağı hipotezi sadece üç modelde anlamlıdır. 1990 yılı gelirinin yanında önce yatırım ve nüfus değişkenleri, sonra da insan sermayesi değişkeni kontrol edildiğinde, sadece Nüfus ve Afrika modellerinde şartlı yakınsama vardır. Elde edilen bulgulara göre yatırım, nüfus ve insan sermayesi kontrol edildiğinde yakınsamanın olacağını net olarak söyleyemiyoruz.

Yukarıdaki modellerde gördüğümüz model değişkenleri (yakın sebepler) büyümeyi açıklayabilmektedir. Fakat, aynı yapısal unsurlara sahip olan ülkelerin aynı durağan denge seviyesinde buluşacakları net değildir. Gelir eşitsizliklerinin giderilememesinin sebebi model koşullarının ülkeler tarafından sağlanamaması olabilir. Modelin rehberliğine rağmen koşulları sağlamadaki başarısızlık koşulları belirleyen temel sebeplerden de (Şans, kültür, Kurumlar, Coğrafya) kaynaklanabilir. Dolayısıyla, elde edilen bu bilgiler ışığında, büyüme hedeflerine ulaşabilmek için koşulları belirleyen temel sebeblere yönelik yapısal reformlara öncelik verilebilir.

\section{Kaynaklar}

Abdioğlu, Z. \&T. Uysal (2013), “Türkiye'de Bölgeler Arası Yakınsama: Panel Birim Kök Analizi”, Atatürk Üniversitesi İktisadi ve İdari Bilimler Dergisi, 27(3), 125-143.

Acemoglu, D. (2009), Introduction to Modern Economic Growth, New Jersey, USA: Princeton University Press.

Akıncı, M. \& Ö. Yılmaz (2012), “Türkiye ile AB Arasındaki Kişi Başına Gelir Yakınsaması: Farklardaki Fark Analizi”, Finans Politik \& Ekonomik Yorumlar, 49(567), 15-26.

Apergis, N. \& E. Panopoulou \& C. Tsoumas (2010), "Old Wine in a New Bottle: Growth Convergence Dynamics in the EU”, Atlantic Economic Journal, 38, 169-181.

Barro, R. (1989), "Economic Growth in a Cross-Section of Countries", NBER Working Papers 3120, National Bureau of Economic Research, Cambridge, Mass.

Barro, R.J. \& X. Sala-i Martin (1991), “Convergence across States and Regions”, Brookings Papers on Economic Activity, 1991(1), 107-182.

Barro, R.J. \& X. Sala-i Martin (1992), “Convergence”, The Journal of Political Economy, 100(2), 223-251.

Bernanke, B.S. \& R.S. Gürkaynak (2001), "Is Growth Exogenous? Taking Mankiw, Romer and Weil Seriously", NBER Working Papers 8365, National Bureau of Economic Research, Cambridge, Mass.

Bianchi C. \& F. Calidoni \& M. Menegatti (2009), "Pitfalls in Estimating beta-Convergence by means of Panel Data: An Empirical Test", Int Rev Econ, 56, 347-357. 
Braudel, F. (2014), Uygarlıkların Grameri, Çev. Mehmet Ali Kılıçbay, Ankara: İmge Kitabevi.

Camarero, M. \& R.G. Flores \& C. Tamarit (2008), “A 'SURE' Approach to Testing for Convergence in Regional Integrated areas: An Application to Output Convergence in Mercosur", Journal of Economic Integration, 23(1), 1-23.

Canova, F. \& A. Marcet (2000), “The Poor Stay Poor: Non-Convergence across Countries and Regions", <http://www.econ.upf.edu/docs/papers/downloads/137.pdf>, 12.12.2015.

Cass, D. (1965), “Optimum Growth in an Aggragative Model of Capital Accumulation”, Review of Economic Studies, 32, 233-240.

Çamurdan, B. \& R. Ceylan (2013), “Gelişmekte olan Piyasa Ekonomilerinin Yakınsama Deneyimi”, Journal of Yasar University, 30(8), 5105-5122.

Dawson, J.W. \& A. Sen (2007), "New evidence on the convergence of international income from a group of 29 Countries", Empirical Economics, 33(2): 199-230.

Desli, E. (2009), "Convergence and Efficiency: Evidence from the EU-15”, Journal of Post Keynesian Economics, 31(3), 403-430.

Domar, E.D. (1946), “Capital Expansion, Rate of Growth, and Employment”, Econometrica, 14, $137-147$.

Durlauf, S. \& P. Johnson \& J. Temple (2005), "Growth Econometrics", (Ed.) P. Agion \& S. Durlauf, Handbook of Economic Growth, Elsevier, 570-754.

Ertur, C. \& K. Thiaw (2005), “Growth and Spatial Dependence”, <http://www-sre.wuwien.ac.at/ersa/ersaconfs/ersa05/papers/660.pdf>, 17.10.2015.

Galvao, A.F. \& F.A. Reis Gomes (2007), “Convergence or Divergence in Latin America? A Time Series Analysis", Applied Economics, 39, 1353-1360.

Giudici, E. \& A.V. Mollick (2008), "Convergence in the Eastern Caribbean States”, Ann Reg Sci 42, 893-909.

Gögül, P.K. \& L. Korap (2014), "Ekonomik Yakınsama Olgusunun Sınanması Üzerine Yeni Bulgular: OECD Örneği”, Kastamonu Üniversitesi İktisadi ve İdari Bilimler Fakültesi Dergisi, 4(2), 60-73.

Islam, N. (1995), "Growth Empirics: A Panel Data Approach”, The Quarterly Journal of Economics, 110 (4), 1127-1170.

Islam, N. (2003), "What have We Learnt from the Convergence Debate?", Journal of Economic Surveys, 17(3), 309-362.

Harrod, R.F. (1939), “An Essay in Dynamic Theory”, Economic Journal, 49, 14-33.

Heston, A. \& R. Summers \& B. Aten (2012), Penn World Table Version 7.1 Center for International Comparisons of Production, Income and Prices at the University of Pennsylvania, November.

Huntington, S.P. (2015), Medeniyetler Çatışması ve Dünya Düzeninin Yeniden Kurulması. Çev. Mehmet Turhan ve Y.Z. Cem Soydemir. İstanbul: Okuyan Us.

Jones, L. \& R. Manuelli (1990), “A Convex Model of Equilibrium Growth: Theory and Policy Implications, Journal of Political Economy, 98(5), 1008-1038.

Koopmans, T.C. (1965), On the Concept of Optimal Economic Growth, In the Econometric Approach to Development Planning, Amsterdam, Elsevier, 225-300.

Lei, C.K. \& S. Yao (2008), “On Income Convergence among China, Hong Kong and Macau”, The World Economy, 31(3), 345-366. 
Liewa, V.K.S. \& Y. Ahmad (2009), "Income Convergence: Fresh Evidence from the Nordic Countries", Applied Economics Letters, 16, 1245-1248.

Lucas, R.E. (1988), "On the Mechanics of Economic Development”, Journal of Monetary Economics, 22, 3-42.

Mankiw, N.G \& D. Romer \& D.N. Weil (1992), “A Contribution to the Empirics of Economic Growth", The Quarterly Journal of Economics, 107 (2), 407-437.

Marcella, D. \& R. Siano (2011), “Time series approaches to Italian regional convergence", Applied Economics, 43(29), 4549-4559.

Masron, T.A. \& Z. Yusop (2008), "Afta, Income Growth, and Income Convergence”, The International Trade Journal, 22(3), 290-314.

Mathur, S.K. (2005), “Absolute and Conditional Convergence: Its Speed for Selected Countries for 1961-2001”, <http://econpapers.repec.org/paper/wpawuwpge/0503002.htm>, 13.12.2015.

McQuinn, K. \& K. Whelan (2006), “Conditional Convergence Revisited: Taking Solow Very Seriously”, <http://www.karlwhelan.com/Papers/mcquinn_whelan_solow.pdf>, 17.10.2015.

Moisescu, E.R. (2015), "Regional Convergence, Case of Romania”, Theoretical and Applied Economics, 22(2), 183-188.

O’Neill, D. \& P. Van Kerm (2008), “An Integrated Framework for Analysing Income Convergence”, The Manchester School, 76(1), 1-20.

Palana, N. \& C. Schmiedeberg (2010), "Structural Convergence of European Countries", Structural Change and Economic Dynamics, 21, 85-100.

Pastor, J.M. \& L. Serrano (2008), "Permanent Income, Convergence and Inequality among Countries", Review of Income and Wealth, 54(1), 105-115.

Ramsey, F. (1928), “A Mathematical Theory of Saving”, Economic Journal, 38, 543-559.

Rapackia, R. \& M. Prochniaka (2010), "Real beta and sigma Convergence in 27 Transition Countries, 1990-2005”, Post-Communist Economies, 21(3), 307-326.

Romer, P.M. (1986), “Increasing Returns and Long Run Growth”, Journal of Political Economy, 94, $1002-1037$.

Romer, P.M. (1990), “Endogenous Technological Change”, Journal of Political Economy, 98, 71102.

Romero-Avilla, D. (2009), “The Convergence Hypothesis for OECD Countries Reconsidered: Panel Data Evidence with Multiple Breaks, 1870-2003”, The Manchester School, 77(4), 552574.

Sala-i Martin, X. (1996), "The Classical Approach to Convergence Analysis", The Economic Journal, 106(437), 1019-1036.

Sarıbaş, H. \& H. Vergil (2013), “İslam Konferansı Teşkilatı’na Üye Ülkelerin Gelir Yakınsaması”, İş Ahlakı Dergisi, 6(1), 111-135.

Solanko, L. (2008), "Unequal Fortunes: A Note on Income Convergence across Russian Regions”, Post-Communist Economies, 20(3), 287-301.

Sorensen, P.B. \& H.J. Whitta-Jacobsen (2010), Introducing Advanced Macroeconomics: Growth and Business Cycles, Glasgow, UK: McGraw-Hill. 
Sousa, C.T. \& E.T. Pereira (2012), “A Contribution to the Empirics of Convergence: the Case of the European State Members”, MPRA Paper No. 62017, University Library of Munich, Germany.

Wu Ho, T. (2006), "Income Threshold and Growth Convergence: A Panel Data Approach", The Manchester School, 74(2), 170-189.

Yeşilyurt, F. (2014), "Yakınsama Hipotezinin OECD Ülkelerinde İkili Yaklaşımla Test Edilmesi”, Sosyal ve Ekonomik Araştırmalar Dergisi, 14(27), 349-358.

Zeren, F. \& V. Yilancı (2011), “Türkiye'de Bölgeler Arası Gelir Yakınsaması: Rassal Katsayılı Panel Veri Analizi Uygulaması", Business and Economics Research Journal, 2(1), 143151. 
Sarıbaş, H. (2016), “Ana Akım Büyüme Modeli ve Yakınsama Hipotezlerinin

Analizi: Panel Veri Yaklaşımı”, Sosyoekonomi, Vol. 24(30), 169-186.

\section{Ek A: Ülke Grupları}

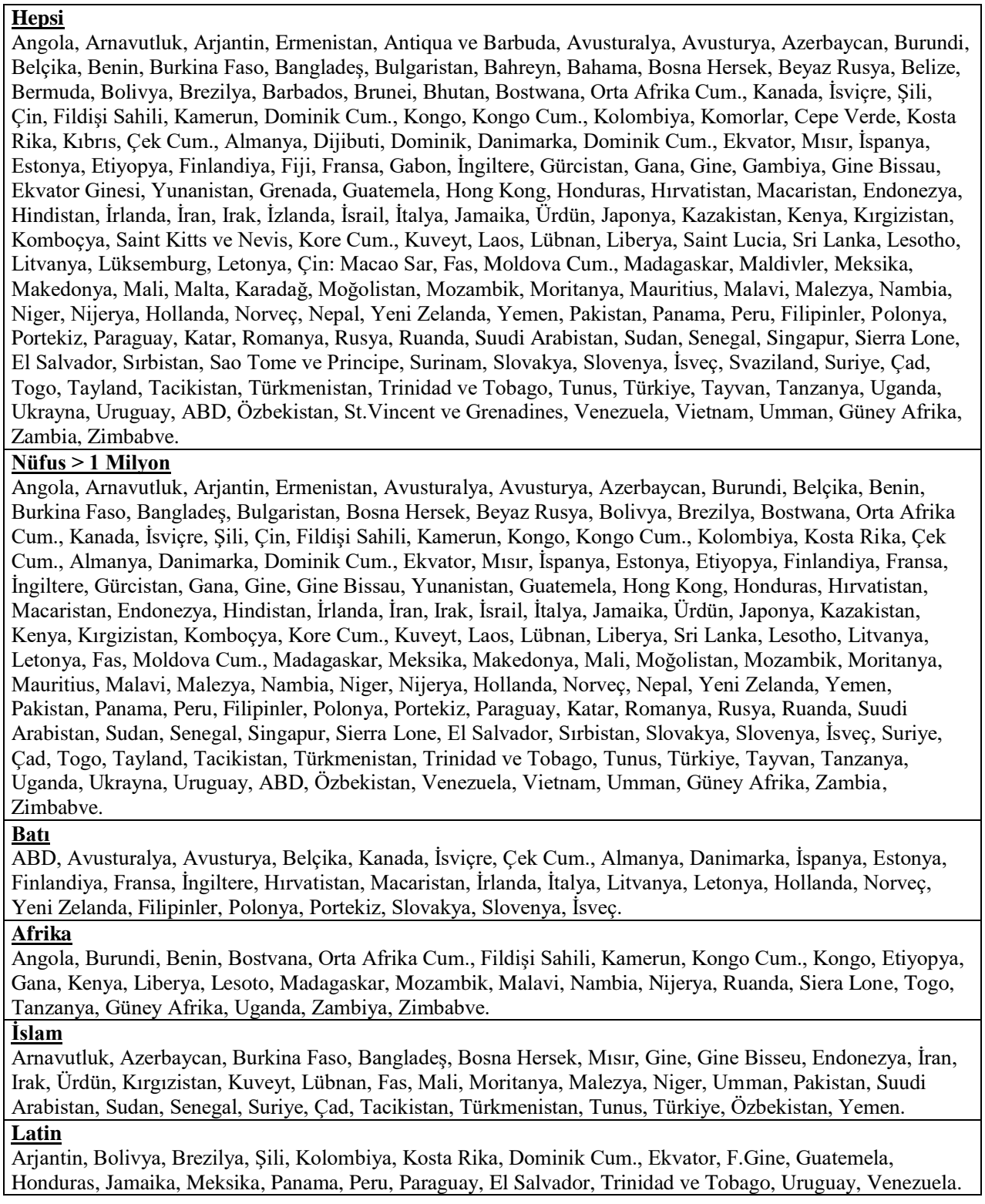

